\title{
Dioscorea nipponica Makino Extract DNE3
}

National Cancer Institute

\section{Source}

National Cancer Institute. Dioscorea nipponica Makino Extract DNE3. NCI Thesaurus.

Code C115103.

An extract of the plant Dioscorea nipponica Makino and inhibitor of both the serine/threonine protein kinase Akt (protein kinase B) and members of the phosphatidylinositol 3-kinase (PI3K) family of lipid kinases, with potential antineoplastic and anti-metastatic activities. Dioscorea nipponica Makino extracted with ethyl acetate (DNE3) binds to and inhibits PI3K and Akt. This inhibits PI3K/Akt-mediated signaling and prevents both growth and survival of PI3K/Akt-overexpressing tumor cells. In addition, DNE3 increases the expression of tissue inhibitor of metalloproteinase-2 (TIMP-2), inhibits the secretion of matrix metalloproteinases (MMPs), primarily MMP-2 and MMP9, and inhibits the serine protease urokinase (urokinase-type plasminogen activator; uPA). This inhibits tumor cell invasion, migration, motility, and adhesion. This agent also inhibits the activation of both CAMP response element-binding (CREB) and activating protein-1 (AP-1), and increases the expression of IkappaB (IkB), which inhibits the activation of nuclear factor-kappa B (NF-kB). These processes further contribute to this agent's anti-tumor potential in susceptible tumor cells. 